\title{
Subdoses de Sulfosate SObRe A InIBIÇÃo dA Atividade dA EPSPS em Plantas de Milho ${ }^{1}$
}

\author{
Sub-Lethal Rates of Sulfosate on the Inhibition of EPSPs Activity in Corn
}

GONÇALVES, A.H. ${ }^{2}$, SILVA, J.B. ${ }^{3}$, SOUZA, I.F. ${ }^{4}$ e PURCINO, A.A.C. ${ }^{5}$

\begin{abstract}
RESUMO - Para avaliar a absorção de subdoses do herbicida sulfosate e a inibição da atividade da EPSPs (5-enolpiruvilshiquimato-3-fosfato sintase), bem como os sintomas visuais de toxicidade na planta de milho (Zea mays), cultivar Cargill 435, foram conduzidos dois experimentos em casa de vegetação da Embrapa Milho e Sorgo, Sete Lagoas-MG, no ano de 2001. No primeiro experimento utilizou-se $10 \%$ da dose recomendada $\left(1,44 \mathrm{~kg} \mathrm{ha}^{-1}\right)$ para o controle das plantas daninhas, com o objetivo de determinar o tempo necessário de absorção do produto. No segundo experimento foram avaliadas nove subdoses de sulfosate nas concentrações de: $0,2,4,6,8,10,12,14$ e $16 \%$ da dose recomendada para se determinar a inibição da atividade enzimática, assim como os sintomas de intoxicação das plantas de milho aos 7, 14, 21 e 28 dias após a aplicação. A planta de milho absorveu 25,2\% do herbicida 24 horas após a aplicação, e essa absorção aumentou com o tempo, até atingir 65,4\% 96 horas após a aplicação. Quanto maior a dose de sulfosate, maior foi a inibição da atividade da EPSPs, 24 horas após a aplicação. Aplicando-se 16\% da dose recomendada, essa inibição atingiu $72,6 \%$ e causou os maiores efeitos fitotóxicos sobre a cultura do milho.
\end{abstract}

Palavras-chave: herbicida, deriva, absorção.

ABSTRACT - To evaluate the effect of herbicide sub-lethal rates of sulfosate on absorption, EPSP synthase activity, and visual symptoms of corn plants (Zea mays), two greenhouse experiments were established at EMBRAPA (Brazilian Agricultural and Livestock Research Institute), in Sete Lagoas-MG, Brazil, in 2001. In one experiment, $10 \%$ of the recommended field rate (1.44 $\left.\mathrm{g} \mathrm{ha}^{-1}\right)$ was tested to determine herbicide absorption time by corn plants and in the second experiment $0,2,4,6,8,10,12,14$ and $16 \%$ of the recommended rate were tested to study EPSPs activity and visual symptoms of phytotoxicity on corn plants. Corn plants absorbed $25.2 \%$ of sulfosate 24 hours after application and absorption increased to $65.4 \%$ at 96 hours. The higher the sulfosate rate, the higher was the EPSPs activity inhibition, 24 hours of application, and more evident the phytotoxicity symptoms on corn plants. At $16 \%$ of the recommended rate, this inhibition reached $72.6 \%$.

Key words: herbicide, drift, absorption.

\section{INTRODUÇÃO}

O milho (Zea mays), por ser uma cultura de elevado potencial produtivo e de alto valor energético, é um dos mais importantes cereais cultivados e consumidos no mundo. Por suas inúmeras aplicações, seja na alimentação humana ou animal, assume relevante papel socioeconômico, além de se constituir em indispensável matéria-prima para diversificados complexos agroindustriais (Fancelli \& Dourado Neto, 1996).

Recebido para publicação em 20/11/2001 e na forma revisada em 9/12/2002.

2 Eng.-Agr., Pós-graduando do Dep. de Agricultura da Universidade Federal de Lavras - UFLA, Caixa Postal 37, $37200-000$ Lavras-MG. ${ }^{3}$ Eng.-Agr., Ph.D., Secretaria Municipal de Agricultura, Meio Ambiente e Desenvolvimento Sustentável, 35700-082 Sete Lagoas-MG. ${ }^{4}$ Eng.-Agr., Ph.D., Dep. de Agricultura da UFLA. ${ }^{5}$ Eng.-Agr., Ph.D., EMBRAPA/CNPMS, Caixa Postal 151, 35701-970 Sete Lagoas-MG. 
O milho é plantado por aproximadamente $60 \%$ dos produtores agrícolas brasileiros (Andrade, 1992). É também uma cultura passível de sofrer influências de vários fatores, como efeitos climáticos, ataque de pragas e doenças e competição das plantas daninhas. Embora todos esses sejam fatores em potencial, um dos que mais influenciam a produtividade de uma lavoura é a presença de plantas daninhas (Duarte, 2000). Segundo Silva (1983), as plantas daninhas são indubitavelmente um dos mais importantes fatores que afetam a economia agrícola em caráter permanente.

O controle de plantas daninhas com herbicidas é uma prática importante na agricultura, pois, além de reduzir o custo de produção e solucionar o problema de escassez de mão-deobra no meio rural, proporciona controle mais rápido e eficiente, comparado aos procedimentos de capina manual e mecânica (Deuber, 1992; Zoschke, 1994). No entanto, para que um herbicida seja utilizado de forma correta e segura, seu uso depende de uma série de fatores ligados à aplicação, ao produto utilizado e às condições climáticas no momento da aplicação.

A deriva do herbicida para áreas não-alvo é uma das complicações que podem ocorrer em decorrência das pulverizações do produto, principalmente quando a aplicação é feita sob condições de vento ou outras condições de ambiente que favoreçam com a sua volatilização e posterior redeposição (Wall, 1994).

Produtos como sulfosate podem atingir culturas vizinhas a grandes distâncias, devido à deriva, cuja intensidade é determinada principalmente por fatores diversos, como condições climáticas e tamanho de gotas. Segundo Silva \& Souza (1988), um aspecto muito preocupante é o crescente número de testemunhos de produtores a respeito da fitotoxicidade causada por derivas em suas lavouras no estádio inicial, principalmente em cultivares precoces de milho. De acordo com Alves (1999), a ocorrência da deriva provoca baixo controle das plantas daninhas, resultando em maiores custos de controle destas plantas e causando sérios prejuízos às espécies não-alvo e ao meio ambiente.

O herbicida sulfosate é classificado como inibidor da síntese dos aminoácidos aromáticos triptofano, tirosina e fenilalanina, por inibir a atividade da enzima EPSPs, reduzindo, dessa maneira, a síntese de proteínas, resultando na paralisação do crescimento das plantas (Rodrigues \& Almeida, 1998). Segundo Vidal (1997), herbicidas inibem a atividade de uma enzima na célula e, como conseqüência, desencadeiam uma série de eventos que matam ou inibem o desenvolvimento da célula e do organismo. Todavia, existem poucas informações que possibilitem quantificar prejuízos à cultura do milho provenientes de derivas de herbicidas e aliá-los à inibição enzimática.

O presente trabalho teve como objetivo avaliar o efeito de subdoses do herbicida sulfosate sobre a inibição da enzima EPSPs, bem como os sintomas visuais de fitotoxicidade dessas subdoses sobre a cultura do milho.

\section{MATERIAL E MÉTODOS}

\section{Avaliação do efeito do tempo de aplicação do sulfosate na atividade da EPSPs}

O delineamento adotado foi o inteiramente casualizado, com três repetições, cujos tratamentos foram constituídos pelo período de observação após a aplicação do produto. As parcelas foram constituídas de um vaso plástico com capacidade de $20 \mathrm{~L}$, cheio com solo coletado a uma profundidade de 0 a $20 \mathrm{~cm}$, peneirado e misturado com fertilizante na fórmula de 08-28-16, de acordo com a análise química do solo. Em cada vaso colocaram-se seis sementes de milho da variedade Cargill 435, a uma profundidade de $5 \mathrm{~cm}$. Seis dias após a germinação das sementes foi feito um desbaste, deixando-se três plantas/vaso. Duas vezes por semana, os vasos foram irrigados com $200 \mathrm{~mL}$ de uma solução nutritiva, que foi preparada dissolvendo-se $50 \mathrm{~mL}$ do adubo líquido Ouro Verde 06-06-08 em 20 L de água.

Na terceira semana após a emergência, no estádio fenológico de 5 a 6 folhas, foi pulverizado o herbicida, utilizando-se pulverizador costal com tanque de 2 litros de capacidade, pressurizado a $\mathrm{CO}_{2}$ bico tipo leque 110.02, pressão constante de $37 \mathrm{lbf} \mathrm{pol}^{-2}$ e volume de aplicação correspondente a $220 \mathrm{~L}$ de calda ha ${ }^{-1}$. Foi aplicada uma dose correspondente a 10\% daquela normalmente recomendada para lavouras comerciais de milho $\left(0,14 \mathrm{~kg} \mathrm{ha}^{-1}\right)$. 


\section{Avaliação do efeito de subdoses de sulfosate na atividade da EPSPs}

Neste experimento determinou-se o efeito de nove subdoses de sulfosate - $0,2,4,6,8$, $10,12,14$ e $16 \%$ da dose normalmente recomendada - aplicadas no estádio de 5 a 6 folhas, na atividade da EPSPs. A coleta das amostras foliares para análise da atividade enzimática foi feita 24 horas após a aplicação do herbicida.

Este experimento foi conduzido em delineamento inteiramente casualizado, com três repetições, e as condições experimentais foram semelhantes às descritas para o experimento anterior.

\section{Avaliação visual dos sintomas de intoxica- ção das plantas de milho}

Os sintomas de intoxicação das plantas de milho foram avaliados inicialmente aos 7,14 , 21 e 28 dias após a aplicação do herbicida, com atribuição de notas, que variaram de 0 (sem sintomas de intoxicação) até 100 (morte total das plantas), segundo metodologia utilizada por Al-Khatib et al. (1992) e Wall (1994).

\section{Extração da EPSPs}

Para extração da EPSPs, foram macerados $2 \mathrm{~g}$ de folhas de cada amostra em $4 \mathrm{~mL}$ de solução-tampão Hepes-NaOH, 57 mM, pH 7,0, contendo $10 \%$ de glicerol, $10 \mathrm{mM}$ de $\beta$ mercaptoetanol, $0,1 \mathrm{mM}$ de EDTA, 0,01 mM de $\left.\left(\mathrm{NH}_{4}\right)_{6} \quad \mathrm{Mo}_{7} \mathrm{O}_{24} 4 \mathrm{H}_{2} \mathrm{O}\right)$ e $10 \%$ de PVPP (polivinilpolipirrolidona). $\mathrm{O}$ macerado foi centrifugado a $5.000 \times g$ por 30 minutos. Após descarte do precipitado, $1 \mathrm{~mL}$ desse extrato foi dessanilizado em colunas de Sephadex G-25 e utilizado como fonte de EPSPs nos ensaios de atividade. Todas essas operações foram realizadas mantendo-se a temperatura entre 2 e $4{ }^{\circ} \mathrm{C}$.

\section{Determinação da atividade da E PSPs}

A atividade da EPSPs foi medida determinando-se a quantidade de $\mathrm{P}$ inorgânico liberada durante a transferência do grupo enolpiruvil do fosfoenolpiruvato (PEP) para o shiquimato3-fosfato (S3P), seguindo-se o protocolo descrito por Forlani et al. (1994). A reação foi medida em $0,1 \mathrm{~mL}$ de um meio de reação contendo
200 mM de Hepes-NaOH, pH 7, 100 mM de shiquimato-3-fosfato, $10 \mathrm{mM}$ do PEP, $5 \mathrm{mM}$ de heptamolibdato de amônio e o extrato cru dessanilizado. Após incubação por 20 minutos a $35{ }^{\circ} \mathrm{C}$, a reação foi paralisada adicionando-se $1 \mathrm{~mL}$ da solução colorimétrica $(9,2 \mathrm{mM}$ de malaquita verde, $8,5 \mathrm{mM}$ de $\left(\mathrm{NH}_{4}\right)_{6} \mathrm{Mo}_{7} \mathrm{O}_{24}$. $4 \mathrm{H}_{4} \mathrm{O}$ em $1 \mathrm{M} \mathrm{HCl}$, adicionando-se $2 \mathrm{~g} \mathrm{~L}^{-1} \mathrm{de}$ CHAPS). Após exatamente um minuto, adicionou-se $0,1 \mathrm{~mL}$ de uma solução de citrato de sódio (34\% p/v). Para o desenvolvimento de cor, deixou-se a mistura descansar à temperatura ambiente por 15 minutos. Antes da determinação da absorbância em 660 nm, os sólidos precipitados foram removidos com uma centrifugação a $2.800 \mathrm{rpm}$, em uma centrífuga clínica de bancada por cinco minutos, seguido de uma passagem em filtro de PVDF com poro de $0,45 \mu \mathrm{m}$. Para leitura no espectrofotômetro (modelo Perkin Elmer - Lambda Bio) foi preparado um controle contendo todos os reagentes, exceto o S3P.

\section{Análise estatística}

Os valores de absorbâncias obtidos nos ensaios foram submetidos à análise de regressão, procurando-se selecionar um modelo matemático que melhor expressasse a relação entre a dose do herbicida utilizada e o tempo após a aplicação. Os programas estatísticos utilizados para essa análise foram o Origin 3.5 e o Sisvar 4.3.

\section{RESULTADOS E DISCUSSÃO}

\section{Absorção do sulfosate pela planta de milho}

A influência do tempo decorrido após a aplicação de uma subdose de sulfosate, correspondente a $10 \%$ da dosagem normalmente recomendada, na atividade da EPSPs pode ser descrita por uma equação quadrática $(\mathrm{Y}=$ $0,8016-0,0094 X+0,000041 X^{2}, R^{2}=0,96$ ) (Figura 1). Na análise desta equação, verificase que o sulfosate reduziu a atividade da EPSPs em 25,20, 44,50, 57,92 e 65,44\% depois de $24,48,72$ e 96 horas, respectivamente, da aplicação do produto. Portanto, em menos de 24 horas após a aplicação de uma subdose de sulfosate na superfície foliar ele conseguiu atingir o cloroplasto, organela onde está localizada a enzima EPSPs (Kruse et al., 2000). 
Quarenta e oito horas após a aplicação, a atividade da EPSPs foi reduzida para praticamente metade $(44,5 \%)$ do valor observado nas plantas controles não tratadas com o herbicida.

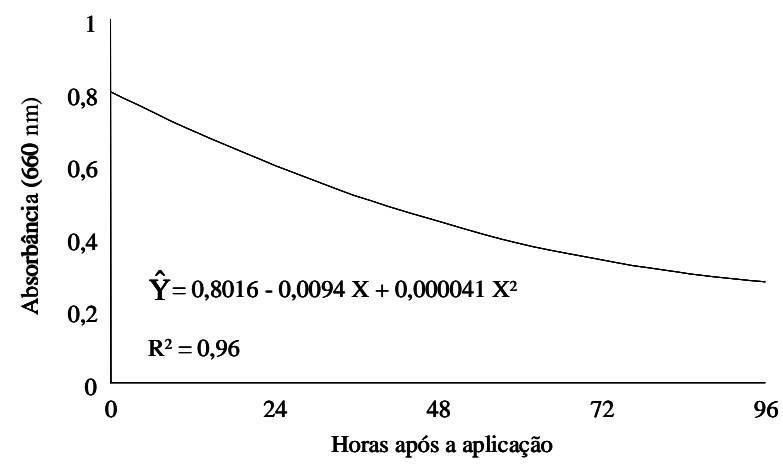

Figura 1 - Efeito de $144 \mathrm{~g} \mathrm{ha}^{-1}$ de sulfosate na atividade da EPSPs em função do intervalo de tempo decorrido desde a aplicação foliar do herbicida, em plantas de milho EMBRAPA/CNPMS, Sete Lagoas-MG, 2002.

\section{Efeito de subdoses de sulfosate na atividade da EPSPs}

O efeito de várias subdoses de sulfosate na atividade da EPSPs em plantas de milho com 5-6 folhas completamente expandidas, 24 horas após a aplicação, é mostrado na Figura 2. Observou-se que a atividade da EPSPs decresceu linearmente $(\mathrm{Y}=1,2340-0,040 \mathrm{X}$, $\mathrm{R}^{2}=0,9412$ ) quando a concentração das subdoses aumentou de $2 \%$ para $16 \%$. Nas condições em que este ensaio foi conduzido, esses dados indicam que a subdose de $2 \%\left(2,8 \mathrm{~g} \mathrm{ha}^{-1}\right)$ causou inibição de 9,07\% na atividade da EPSPs 24 horas após a aplicação do herbicida. A inibição causada pela subdose de $16 \%\left(22,40 \mathrm{~g} \mathrm{ha}^{-1}\right)$ foi de $72,6 \%$.

Esses resultados estão de acordo com trabalhos realizados por Singh \& Shaner (1998), que verificaram injúrias causadas em plantas não-alvo pelo de uso de glyphosate. Esses autores relataram que os danos causados foram devidos ao acúmulo de shiquimato pela inibição da enzima EPSPs.

O estádio de desenvolvimento da cultura é um fator de importância com relação aos efeitos causados pelo herbicida usado. Trabalho realizado por Hurst (1982), na cultura do algodão (Gossypium hirsutum), mostrou que o estádio inicial de desenvolvimento foi sensivel quando se utilizaram bifenox e metribuzin. Também Bailey \& Kapusta (1993) verificaram que subdoses de primisulfuron e nicosulfuron, sobre a cultura de soja (Glycine max), causaram efeitos danosos no início de desenvolvimento da cultura.

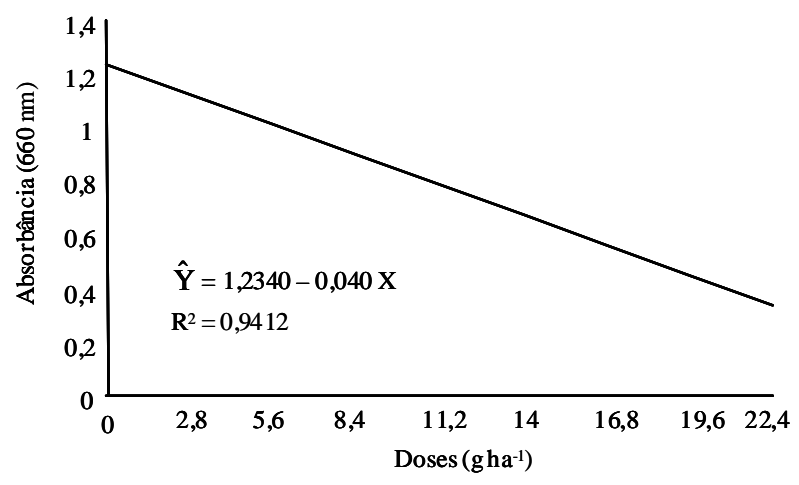

Figura 2 - Efeito de subdoses de sulfosate na atividade foliar da EPSPs 24 horas após a aplicação do herbicida em planta de milho. EMBRAPA/CNPMS, Sete Lagoas-MG, 2002.

\section{Avaliação dos sintomas visuais de intoxi- cação das plantas de milho}

Os valores médios das notas dadas aos sintomas de ntoxicação das plantas de milho aos $7,14,21$ e 28 dias após a aplicação do herbicida (DAA) podem ser observados na Figura 3.

Nas avaliações realizadas aos 7 e 14 DAA houve aumento linear dos sintomas de intoxicação à medida que as subdoses foram aumentadas. Comportamento semelhante também pode ser observado para as avaliações aos 21 e 28 DAA, porém os modelos de equação foram de raiz cúbica.

Verificou-se que, nas avaliações realizadas aos 21 e 28 dias após a aplicação, o efeito fitotóxico foi maior, atingindo, nas doses de $14 \mathrm{e}$ $16 \%$, valores de 74,64 a $88,77 \%$ para 21 dias e de 87,91 e $97,98 \%$ para 28 dias após a aplicação do herbicida.

Esses efeitos de intoxicação, devido ao mecanismo de ação do sulfosate, são perceptíveis apenas alguns dias após a aplicação, como citado por Ahrens (1994) e Rodrigues \& Almeida (1998). Por esse motivo, o tratamento com sulfosate apresentou menor efeito fitotóxico nas 


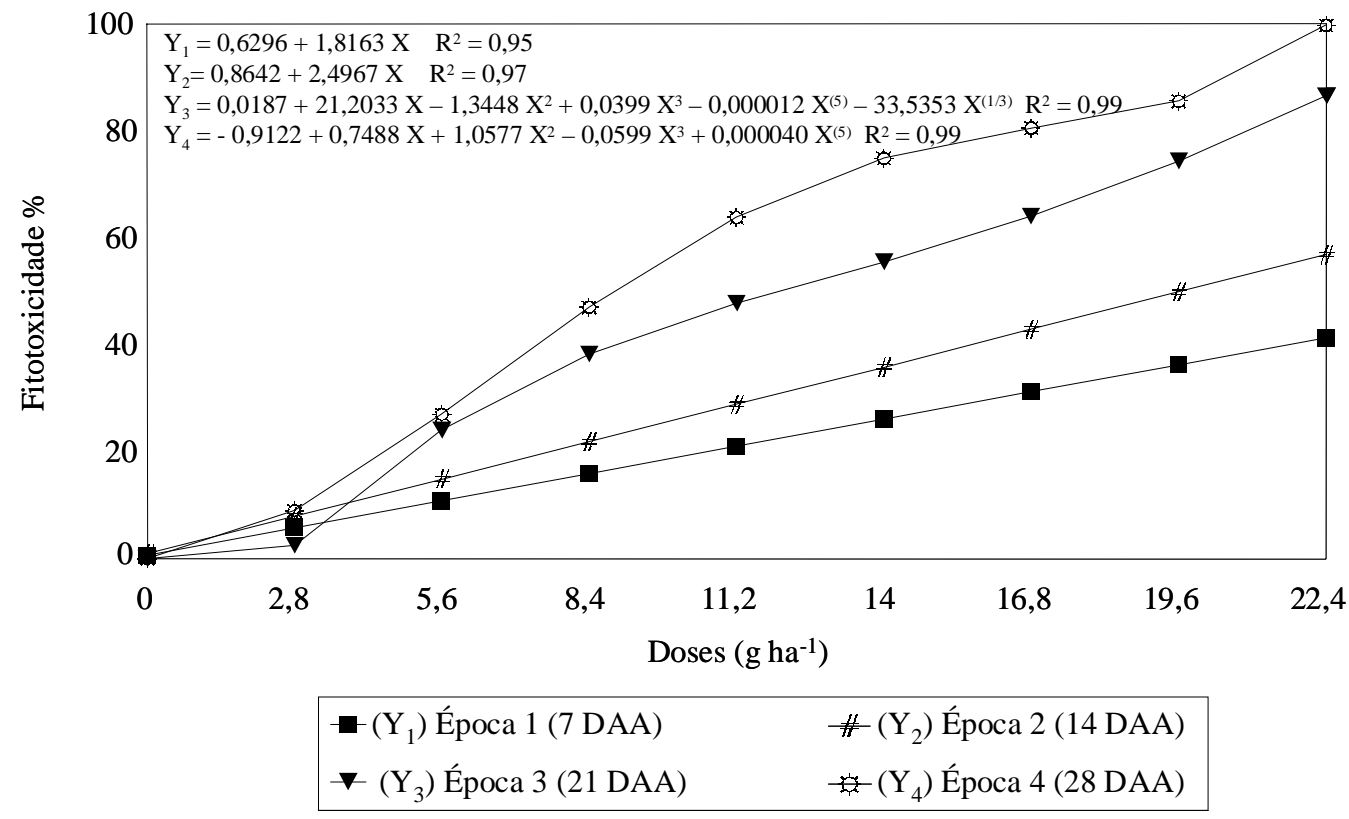

Figura 3 - Equações de regressão entre subdoses de sulfosate e as respectivas respostas de injúrias (\%), com avaliações aos 7, 14, 21 e 28 DAA. EMBRAPA/CNPMS, Sete Lagoas-MG, 2002.

primeiras avaliações. Esses resultados indicam que os efeitos de tratamentos com subdoses de herbicidas simulando deriva são dependentes do herbicida, da dose e do estádio de desenvolvimento da cultura no momento da aplicação (Eberlein \& Guttieri, 1994).

Com base nas condições experimentais deste estudo e nos parâmetros analisados, constatou-se que o herbicida sulfosate, quando em contato com a planta de milho, na dose de $144 \mathrm{~g} \mathrm{ha}^{-1}$, apresenta efeito inibitório da EPSPs 24 horas após a aplicação, chegando a inibir 65,44\% da atividade da enzima 96 horas após a aplicação.

Quanto maior a subdose utilizada de sulfosate, maior a inibição da atividade da EPSPs, indicando maior absorção do herbicida.

Os sintomas de intoxicação provocados nas plantas de milho foram proporcionais ao aumento dessa inibição, em razão do aumento das subdoses do produto, resultando em maior efeito fitotóxico.

\section{LITERATURA CITADA}

AHRENS, W. H. Herbicide handbbook. 7.ed. Champaign: Weed Science Society of America, 1994. 352 p.
AL-KHATIB, K.; PARKER, R.; FUERST, E. P. Foliar absorption and translocation of herbicides from aqueous solution and treated soil. Weed Sci., v. 40, n. 2, p. 281-287, 1992.

ALVES, L. W. R. Efeito da aplicação de subdoses dos herbicidas glyphosate e oxyfluorfen, simulando deriva sobre a cultura do milho (Zea mays L.). Lavras: Universidade Federal de Lavras, 1999. 80 p. Dissertação (Mestrado em Fitotecnia) - Universidade Federal de Lavras, 1999.

ANDRADE, J. B. A cultura do milho. Guaxupé: COOXUPÉ, 1992. 64 p. (Boletim Técnico).

BAILEY, J. A.; KAPUSTA, G. Soybean (Glycine max) tolerance to simulated drift of nicosulfuron and primisulfuron. Weed Technol., v. 7, n. 3, p. 740-75-45, 1993.

DEUBER, R. Ciência das plantas daninhas: fundamentos. Jaboticabal: FUNDEP, 1992. $431 \mathrm{p}$.

DUARTE, N. F. Determinação do período de competição de plantas daninhas fundamentado nos estádios fenológicos da cultura do milho (Zea mays L.). Lavras: Universidade Federal de Lavras, 2000. 81 p. Dissertação (Mestrado em Fitotecnia) - Universidade Federal de Lavras, 2000 .

EBERLEIN, C. V.; GUTTIERI, M. J. Potato (Potato tuberosum) response to simulate drift of imidazoline herbicides. Weed Sci., v. 42, n. 1, p. 70-75, 1994.

Planta Daninha, Viçosa-MG, v.20, n.3, p.465-470, 2002 
FANCELLI, A. L.; DOURADO NETO, D. Milho: fisiologia da produção. In: SEMINÁRIO SOBRE FISIOLOGIA DA PRODUÇÃO E MANEJO DE ÁGUA E DE NUTRIENTES NA CULTURA DO MILHO DE ALTA PRODUTIVIDADE, 1996, Piracicaba. Anais... Piracicaba: ESALQ/USP/POTAFOS, 1996. p. 1-26.

FORLANI, G.; PARISI, B.; NIELSEN, E. 5-enol-PyruvylShikimate-3-Phosphate Synthase from Zea mays Cultured Cells. Plant Physiol., v. 105, p. 1107-1114, 1994.

HURST, H. R. Cotton (Gossipium hirsutum) response to simulated drift from selected herbicides. Weed Sci., v. 30, n. 3, p. 311-315, 1982.

KRUSE, N. D.; TREZZI, M. M.; VIDAL, R. A. Herbicidas inibidores da EPSPS: revisão de literatura. R. Bras.

Herbic., v. 1, n. 2, p. 139-146, 2000.

RODRIGUES, B. N.; ALMEIDA, F. S. Guia de

herbicidas: contribuição para uso adequado em plantio direto. 4.ed. Londrina: IAPAR, 1998. 648 p.
SILVA, J. F. Defensivos agrícolas, utilização, toxicologia e legislação específica: herbicidas. Brasília: ABEAS, 1983. $161 \mathrm{p}$.

SILVA, J. B.; SOUZA, J. L. Tolerância de cultivares precoces de milho (Zea mays L.) a cyanazine. In: CONGRESSO NACIONAL DE MILHO E SORGO, 17. 1988, Piracicaba. Resumos... Piracicaba: ESALQ/USP, 1988. p. 31-32.

SINGH, B. K.; SHANER, D. L. Rapid determination of glyphosate injury to plants and identification of glyphosateresistant plants. Weed Technol., v. 12, p. 527-530, 1998.

VIDAL, R. A. Herbicidas: mecanismos de ação e resistência de plantas. Porto Alegre: UFRGS, 1997. 165 p.

WALL, D. A. Potato (Solanum tuberosum) response to simulated drift of dicamba, clopyralid, and Tribenuron. Weed Sci., v. 42, n.1, p. 110-114, 1994.

ZOSCHKE, A. Toward reduced herbicide rates and adapted weed management. Weed Technol., v. 8, p. 376-386, 1994. 